\title{
Construcionismo Social e Metapsicologia: Um Diálogo sobre o Conceito de Self
}

\author{
Carla Guanaes e Marisa Japur ${ }^{1}$ \\ Universidade de São Paulo, Ribeirão Preto
}

\begin{abstract}
RESUMO - O conceito de self tem sido central nas teorias da psicologia clínica, sendo difícil encontrar, neste campo, estudos que prescindam desta noção. Contudo, alguns teóricos têm questionado concepções mais conhecidas de self, apontando seu caráter construído e situado. Neste artigo, apresentamos o modo como o self tem sido descrito em algumas propostas psicanalíticas e construcionistas sociais, visando a construção de algumas diferenças entre elas. Buscamos, assim, favorecer uma aproximação de estudiosos da área clínica com o construcionismo social, entendendo que esta abordagem favorece uma reflexão sobre o próprio processo de produção de conhecimento sobre o mundo e sobre o self.
\end{abstract}

Palavras-chave: construcionismo social; teoria psicanalítica; self.

\section{Social Constructionism and Metapsychology: A Dialogue about the Concept of Self}

\begin{abstract}
The concept of self had become central in clinical psychology, in such a way that it is hard to find a theory that doesn't make use of it. However, some theorists have criticized some traditional concepts of self, emphasizing their constructed and local nature. Our aim is to present how this concept has been described in some psychoanalytic and constructionist approaches, thus favoring an understanding about their differences. With this, we intend to favor an approach of therapists with social constructionism, once this perspective has promoted a critical view about the way we construct meanings about the world and the self.
\end{abstract}

Key words: social constructionism; psychoanalitic theory; self.

O conceito de self tem se constituído central na maioria das teorias psicológicas da área clínica, sendo praticamente impossível, neste campo, imaginar uma teoria que prescinda desta noção. Para além deste campo específico, a própria definição de Psicologia ${ }^{2}$ pressupõe a noção de self, assumindo a idéia de indivíduo como sendo constituído por disposições internas e mentais - noções que hoje integram grande parte das significações de nossa cultura ocidental sobre este tema.

As teorias psicanalíticas constituem um exemplo do uso destas noções de indivíduo e self no entendimento do funcionamento humano. Estas destacam-se pelo grau de elaboração teórico-conceitual com que abordam a questão do psiquismo e do self, tendo grande influência na formação profissional e, por conseguinte, na disseminação da Psicologia ao domínio público.

Contudo, de acordo com Sampson (1989), nos anos recentes, muitos estudos e tendências teóricas têm desafiado estas concepções mais conhecidas de self, sobretudo apontando para a peculiaridade desta concepção ocidental de homem, indicando a possibilidade de outras concepções menos individualizantes; e para o caráter construído e situado, social e culturalmente, de termos como self, personalidade e traços individuais, assim questionando o caráter natural e essencial destas descrições. Nesta mesma direção, muitos autores construcionistas têm proposto um novo entendimento sobre

1 Endereço: Av. Bandeirantes, 3900 - Ribeirão Preto (SP) - CEP 14040901. E.mail: mjapur@ffclrp.usp.br

2 De acordo com o dicionário da língua portuguesa, entende-se por Psicologia "1) a ciência dos fenômenos psíquicos e do comportamento. 2) conjunto de estados e disposições psíquicas e mentais de um indivíduo ou grupo de indivíduos." (Aurélio, 1977). o self, onde este é visto como um discurso, uma construção social, produto das práticas discursivas nas quais as pessoas dão sentido ao mundo e a suas próprias ações.

A proposta construcionista social vem ganhando destaque entre as ciências psicológicas nos últimos anos, sobretudo entre os teóricos da psicologia social. Contudo, ela ainda tem sido recebida com receio no campo da psicologia clínica, onde se questiona a proposta de um self discursivo, entendendo que este conceito sugere um self "esvaziado" e "sem conteúdo", onde não há espaço para a experiência individual.

Entendendo ser esta uma discussão bastante polêmica e interessante, buscamos, neste artigo, apresentar o modo como o self tem sido descrito em algumas teorias psicológicas mais tradicionais e em algumas propostas construcionistas, na tentativa de favorecer a construção de algumas diferenças entre estes campos. A escolha pelas teorias psicanalíticas, dentre as demais teorias psicológicas, justifica-se pela centralidade do discurso metapsicológico na concepção hegemônica do self em nossa sociedade.

Não pretendemos, na realização desta tarefa, comparar as descrições psicanalíticas com a perspectiva construcionista, de modo a afirmar a superioridade de uma sobre a outra. Ao contrário, buscamos entender estas produções como versões possíveis, situadas e fundamentadas sob uma determinada visão de ciência e de mundo, sendo nosso objetivo apenas facilitar a apreensão das principais diferenças entre elas.

Assim, apresentamos inicialmente o modo como o conceito de self tem sido descrito em algumas abordagens psicanalíticas, a partir de três vertentes clássicas: a psicologia do ego, a teoria das relações objetais, e a psicologia do self. 
Em seguida, situamos o modo como tem se dado a discussão sobre o self entre alguns teóricos construcionistas, destacando também três perspectivas: a noção de pessoa como usuária do discurso, a teoria de posicionamento, e a noção de self narrativo. Por fim, propomos um diálogo entre estas propostas, buscando construir algumas diferenças entre elas e, em especial, favorecer uma aproximação de profissionais e estudiosos em psicologia clínica com o construcionismo social.

\section{Um olhar sobre o conceito de self em algumas abordagens psicanalíticas}

\section{A psicologia do ego e o conceito de self}

A psicologia do ego é derivada da teoria psicanalítica clássica de Sigmund Freud que se constitui por um conjunto de hipóteses acerca do funcionamento da mente humana sustentadas, sobretudo, por dois princípios: 1) o do determinismo psíquico ou da causalidade, que postula que todo evento psíquico é determinado por eventos precedentes, de modo que não há acasos na vida mental; e 2) o da existência do inconsciente que, embora não seja passível de observação direta, manifesta-se, de diferentes modos, na vida mental (Brenner, 1987).

Buscando explicar o funcionamento do psiquismo humano, Freud (1969/1900) propôs inicialmente um modelo topográfico da mente, onde esta foi dividida em três áreas ou regiões específicas: o consciente; o pré-consciente e o inconsciente. Na evolução de sua teoria, este modelo foi substituído pela proposição da teoria estrutural, que caracteriza mais propriamente o que hoje entende-se como psicologia do ego. Embora Freud tenha mantido a importância da dinâmica dos processos conscientes, pré-conscientes e inconscientes, em sua teoria estrutural estes passaram a ser descritos em termos de conflitos e estruturas psíquicas: 1) o id - reservatório de pulsões desordenadas; 2) o ego - órgão executivo, responsável pelo controle da motilidade, percepção e contato com a realidade, bem como pelo adiamento e modulação na expressão dos impulsos; e 3) o superego - responsável por estabelecer e manter a consciência moral da pessoa, a partir de ideais e valores internalizados através das relações com as figuras parentais (Kaplan, Sadock \& Grebb, 1997).

Assim, Freud postula a existência de um mundo psíquico interno, organizado em termos de conflito entre instâncias, onde há uma batalha entre o superego e o id frente às demandas da sexualidade e da agressividade por expressão e descarga (Gabbard, 1998). Este conflito gera ansiedade, que sinaliza ao ego a necessidade de mecanismos defensivos, isto é, de processos mentais que defendam o ego do perigo da invasão de impulsos e conteúdos inconscientes. O modo como o aparelho psíquico organizará a experiência pessoal, lidando com as necessidades pulsionais próprias a cada estágio do desenvolvimento (descrito por Freud a partir do esquema clássico das zonas erógenas), fundamenta a compreensão da personalidade e da formação de traços de caráter.

Alguns psicanalistas contemporâneos (Blum, 1982; Meissner, 1986; Ticho, 1982) têm apontado a dificuldade de apreensão do conceito de self na obra freudiana, sobretudo pela ambigüidade do termo alemão (Ich) utilizado, que pode ser traduzido tanto por ego como por self. De acordo com Strachey (1961, conforme citado em Ticho, 1982):

“...pode-se detectar dois principais usos [de Ich]: um em que o
termo distingue o self de uma pessoa como um todo (incluindo
talvez o seu corpo) de uma outra pessoa, e o outro e que denota
uma parte particular da mente, caracterizada por atributos e
funções especiais...” (p. 850)

Este uso ambíguo do termo Ich por Freud é também referido por Kernberg (1982), que sugere que este pode ser entendido tanto por ego (estrutura mental) como por self (experiência mais pessoal, subjetiva e experiencial). Deste modo, Freud teria aplicado o termo não apenas para referirse ao ego, conceito específico de sua teoria estrutural, como também para falar da experiência subjetiva e da auto-estima. Contudo, temos apenas uma definição sistematizada na obra freudiana do que vem a ser o Ich enquanto ego, parecendo haver uma ausência de preocupação do autor em definir este termo quando usado em referência a experiência pessoal subjetiva.

\section{A teoria das relações objetais e o conceito de self}

Os termos self e ego também aparecem referidos na teoria das relações objetais, que tem em Melanie Klein e W. Winnicott seus principais representantes.

Segundo Gabbard (1998), enquanto os teóricos da psicologia do ego tendem a minimizar a importância do self, dando maior ênfase às funções egóicas, os teóricos das relações objetais enfatizam o self em suas relações com os objetos, assim clarificando a posição do self no aparelho psíquico. Para eles, o self desenvolve-se como resultado das interações com objetos significativos do ambiente e com objetos internos relacionados.

Contrariamente à psicologia do ego, que defende que as pulsões são primárias às relações de objeto, os teóricos das relações objetais afirmam que os impulsos emergem no contexto de um relacionamento, sendo as relações objetais anteriores às pulsões. Apesar desta distinção, mantém-se o entendimento acerca da importância dos processos inconscientes e dos mecanismos defensivos empregados contra as tendências pulsionais.

Klein, por exemplo, adota o modelo estrutural proposto por Freud, assumindo a noção de inconsciente e a importância da sexualidade para o desenvolvimento infantil e formação da personalidade (Klein, 1970). Partindo destes princípios, ela desenvolve outras contribuições para psicanálise, como a noção de fantasias inconscientes e considerações sobre o desenvolvimento primitivo da criança (Daniel, 1994).

De acordo com Klein, é a partir da internalização da figura materna (introjeção) que a criança vai desenvolver a sua própria representação de self, primeiro a partir de uma representação corpórea, depois através do conjunto de sensações e experiências percebidas como próprias. Ou seja, é através dessa relação objetal primária que a criança adquire um senso de si mesma, de um self separado e distinto de sua mãe.

Também Klein adota uma concepção evolutiva da personalidade, descrevendo estágios do desenvolvimento infantil 
associados à vivência de ansiedades básicas, derivadas de fantasias primitivas inconscientes. Ela pressupõe que o ego é, desde o nascimento, capaz de formar relações objetais, na fantasia ou na realidade, impulsionado seja pelos instintos seja pela ansiedade (Segal, 1975).

De acordo com Hinshelwood (1992), Klein não usou o termo ego de maneira tão precisa quanto Freud o fez ao propor seu modelo estrutural, mas sim de modo intercambiável com o termo self. Ela postulou um ego que já existe no nascimento, que tem uma fronteira e que identifica objetos, caracterizado pelo exercício de funções primitivas como separar o eu do não-eu; discriminar entre o bom e o mau; e criar fantasias como de introjeção e projeção, entre outras. Sobre o uso do termo self por Klein, Hinshelwood (1992) afirma:

\footnotetext{
"Se o 'ego' representa uma parte da estrutura da mente, obviamente descrita, o self tende a representar o sujeito em suas próprias fantasias, descritas a partir de um ponto de vista subjetivo. $O$ self tenderia então a expressar o aspecto relacional das teorias de Klein...” (p. 300/301).
}

A despeito destas imprecisões no uso dos termos ego e self, pode-se dizer, em síntese, que a visão kleiniana de homem pressupõe a existência de um complexo mundo interno, resultante das fantasias inconscientes infantis, nas quais objetos são introjetados e colocados em relação dinâmica uns com os outros e com o próprio ego. A partir disso, entende-se que o quê determinará o caráter de uma pessoa é a natureza de suas fantasias inconscientes e o modo como estas se relacionam à realidade externa (Segal, 1975).

Também afinado com a proposta da teoria das relações objetais pela ênfase que atribui às relações objetais internas, encontra-se Donald W. Winnicott. Ele foi um dos precursores de uma nova direção no pensamento psicanalítico, voltandose mais diretamente ao estudo da identidade e do self, em detrimento do estudo dos instintos e dos mecanismos defensivos do ego. Assim, ele formulou uma concepção de mundo interno bastante original, distanciando-se da teoria freudiana por não recorrer à teoria pulsional como recurso explicativo, e também da teoria kleiniana, por retirar a ênfase sobre o mundo interno da criança e suas fantasias inconscientes.

Winnicott destaca a influência do ambiente inicial da criança e da qualidade de suas relações primárias no processo de constituição do self. Para ele, existem duas tendências básicas relacionadas ao processo de desenvolvimento infantil: a tendência à maturação, que é herdada, e a tendência à dependência, que se refere às condições fornecidas pelo ambiente para o adequado amadurecimento humano (Santos, 1999). Para Winnicott (1993a), é a relação mãe-bebê (mãe enquanto figura cuidadora) que torna possível a formação do self. Ou seja, a realidade externa atua como importante aliada dos processos maturativos, sendo a mãe parte desta realidade, parte deste ambiente fundamental para a personalização do potencial psíquico e pulsional do bebê.

Winnicott (1993a) defende a importância do desenvolvimento primitivo infantil para a formação do self, que inclui três processos: 1) a integração - percepção do self como algo integrado, resultante da capacidade de diferenciação entre eu e não-eu; 2) a personalização - desenvolvimento do sentimento que se está dentro do próprio corpo; e 3) a realização - desenvolvimento da apreciação do tempo e do espaço, bem como de outras propriedades da realidade. Para o desenvolvimento normal de um indivíduo, estes três processos devem ser realizados e, para isto, tanto o recebimento de cuidados na infância como as experiências pulsionais são fundamentais (Winnicott, 1993b).

Winnicott concebe, ainda, que no processo de desenvolvimento do bebê pode emergir tanto um verdadeiro self, constituído no contexto de um ambiente mantenedor, produzido por uma mãe suficientemente boa; como um falso self-que emerge quando os bebês experimentam alguma perturbação traumática durante o desenvolvimento de seu senso de self (Kaplan \& cols. 1997). Contudo, como todos nós estivemos supostamente expostos a frustrações e experiências não gratificantes, todos temos aspectos de falso self, sem que isso necessariamente sinalize patologias: "o que importa é o grau de falso self que há em cada um de nós e a possibilidade desse falso self bloquear o funcionamento do verdadeiro self' (Mello Filho, 1005, p.115).

Ao contrário de Freud e Klein, para quem a noção de self permanece mais difusa, Winnicott apresenta uma definição de self bastante particular:

“... o self, que não é ego, é a pessoa que eu sou, que é somente eu, que possui uma totalidade baseada na operação do processo maturativo. Ao mesmo tempo, o self tem partes e é, na verdade, constituído destas partes. Tais partes se aglutinam, num sentido interior-exterior no curso da operação do processo maturativo, auxiliado, como deve sê-lo (principalmente no início) pelo ambiente humano que o contém, que cuida dele e que de certa forma ativa facilita-o..." (Winnicott, 1971, conforme citado por Khan, 1993, p. 45).

A ênfase de Winnicott nos aspectos ambientais e, especificamente, na importância da função materna, faz com que ele seja reconhecido como uma das figuras centrais na escola britânica das relações objetais.

\section{Heinz Kohut e a proposição de uma psicologia do self}

A tentativa de encontrar um lugar para o self na teoria psicanalítica assume sua forma mais explícita nos escritos de Heinz Kohut, derivando na proposição de uma psicologia do self. Esta representa um marco no curso do pensamento psicanalítico, gerando polêmica quanto à possibilidade de constituir uma abordagem teórico-clínica, nova e, portanto, distinta das correntes psicanalíticas precedentes.

Kohut afirma que o desenvolvimento do indivíduo depende da consolidação de um self, definido como uma estrutura supra-determinada, resultante das interações com o ambiente psicológico e independente do referencial estrutural freudiano (Mello Filho, 1995). Suas concepções originaram-se a partir de observações sobre particularidades do funcionamento emocional de pacientes com transtornos narcisistas. Segundo ele, estes pacientes organizam dois tipos de relação transferencial: 1) a transferência especular - na qual o paciente espera respostas confirmatórias do analista, tal como as respostas de aprovação materna às atitudes exibicionistas da criança; e 2) a transferência idealizadora - na qual o paciente percebe o terapeuta como um genitor todo poderoso, idealizado, ca- 
paz de propiciar paz e cura. A partir disso, Kohut considera que receber respostas aprovatórias nos relacionamentos e ter nos genitores um modelo de idealização são aspectos essenciais para o desenvolvimento normal infantil. Falhas nestes aspectos podem levar à fragmentação no sentido de self da criança, gerando respostas inapropriadas, expressas por uma busca desesperada seja por perfeição e admiração, seja por um elevado ideal de ego (Gabbard, 1998).

Para Kohut, o modelo estrutural do conflito psíquico proposto pela psicologia do ego é insuficiente para explicar tais necessidades narcísicas de espelhamento e idealização. Por isso, sua visão de self contempla uma descrição do narcisismo humano, entendendo que as necessidades narcísicas persistem por toda a vida adulta, caracterizando todas as relações objetais ao longo do desenvolvimento (Havens, 1986).

Kohut atribui ênfase especial ao papel que as outras pessoas exercem para o desenvolvimento do self, à medida que respondem a estas necessidades de espelhamento, idealização e gemealidade. Nos primórdios do desenvolvimento, os outros não são vistos como separados, mas como objetos do self, que têm a função única de atender suas necessidades. Esta necessidade de objetos do self nunca é superada, nem mesmo na vida adulta, uma vez que sempre precisamos de objetos de self em nosso ambiente para nossa sobrevivência emocional (Gabbard, 1998).

Tal como destaca Gabbard (1998), a diferença entre a teoria das relações objetais e a psicologia do self é que enquanto a primeira enfatiza os relacionamentos internalizados entre as representações do self e dos objetos, a outra aponta para a importância dos relacionamentos externos para a manutenção do senso de auto-estima e coesão do self. O foco da psicologia do self, portanto, recai sobre a necessidade individual de obter respostas dos outros para desenvolver o senso de bem estar pessoal, sendo por isso, muitas vezes entendida como uma psicologia bi-pessoal.

Kohut (1988) desenvolve extensamente a noção de self, defendendo um lugar especial para este conceito na teoria psicanalítica. Para ele, o self não se constitui "o centro de nosso ser", de onde se originam todas as nossas iniciativas e experiências, mas sim "um conteúdo da mente potencialmente observável", que se revela múltiplo através da observação psicanalítica. Tal como sugere, podemos reconhecer, em análise,

\footnotetext{
“ a existência simultânea de selves diferentes e até mesmo contraditórios na mesma pessoa, de selves com variados graus de estabilidade e diversos graus de importância. Há selves conscientes, pré-conscientes e inconscientes; há selves no ego, no id e no superego, e podemos descobrir, em alguns de nossos pacientes, selves incompatíveis, lado a lado, na mesma instância psíquica” (p. 32/33).
}

Apesar desta diversidade possível de selves, Kohut postula um self mais centralmente localizado na psique, ao qual denomina de self nuclear. Este contém conteúdos derivados tanto do self grandioso (propósitos e ambições de auto-afirmação) como da imagem parental idealizada (valores idealizados). Embora relativamente estável em sua constituição, o self nuclear não é imutável, podendo sofrer alterações ao longo do processo vital, através da influência de fatores internos e externos.
Assim, a psicologia do self não enfatiza, tal como a psicologia do ego, as pulsões biológicas e a dinâmica do aparelho psíquico (Kohut, 1988), mas se aproxima da teoria das relações objetais, ao assumir a centralidade das figuras parentais na formação do self. Contudo, é o maior desenvolvimento da noção de self que garante à ela um lugar de destaque entre as demais teorias psicanalíticas (Gabbard, 1998).

Através desta apresentação, notamos a inexistência de um consenso sobre o modo como o selfé descrito nas teorias psicanalíticas. E, frente a esta diversidade de concepções, é bastante complexa a tarefa de comparar estas abordagens sem incorrer no erro de subestimar suas diferenças. Assim, buscamos aqui apreender alguns dos fundamentos teóricos centrais que aglutinam estas diferentes descrições sob uma mesma malha teórica e, neste exercício, concluímos que a pressuposição de um mundo interno e de um aparelho psíquico, cujo funcionamento é marcado pela dinâmica de processos mentais inconscientes, é elemento comum em todas estas abordagens, sendo justamente o que as inclui sob o domínio de uma metapsicologia (Garcia-Rosa, 1995).

\section{A perspectiva construcionista social e a proposição de um self discursivo}

No contexto dos estudos pós-modernos, o construcionismo social surge como uma alternativa às formas empiricistas de se conceber a ciência e os processos de produção de conhecimento, abrindo novas reflexões no campo das ciências humanas e sociais. Tal como descrito por Shotter (2000), o construcionismo social busca investigar o contínuo fluxo da atividade comunicativa humana, dando destaque aos processos linguiísticos e relacionais que possibilitam a produção de conhecimento sobre o self e sobre o mundo em que vivemos.

Comum às muitas propostas construcionistas é a noção de que o self depende das práticas discursivas através das quais as pessoas dão sentido ao mundo e às suas próprias ações - ou seja, o self é entendido enquanto uma construção social, produto das trocas discursivas situadas. Ele pode ser considerado como uma expressão da capacidade para a linguagem e a narração, sendo definido a cada momento de uma interação através dos modos pelos quais as pessoas descrevem a si mesmas (e são descritas por outras) em suas conversações (Gergen, 1991; 1994; Harré, 1998; Harré \& Van Langenhove, 1999a; Potter \& Wetherell, 1996; Shotter, 1998; 2000).

Tal como Burr (2000), reconhecemos ao menos três descrições construcionistas sobre a natureza discursiva do self: 1) a proposta de uma psicologia discursiva de Potter e Wetherell (1996); 2) a teoria do posicionamento de Harré e Van Langenhove (1999a) e 3) a noção de self narrativo de Gergen (1994). A seguir, apresentamos cada uma delas, buscando dar visibilidade também à amplitude de descrições sobre o self que circulam no campo dos estudos construcionistas.

\section{A pessoa como usuária do discurso}

Confrontando algumas noções hegemônicas sobre a natureza do self, Potter e Wetterell (1996) propõem uma psicologia discursiva, que tem por objetivo compreender os modos como 
as versões de self são construídas na interação entre as pessoas, as práticas sociais que são engendradas através delas, e como a pessoa se constitui de modos diferentes, através das formas pelas quais se descreve em determinadas ocasiões.

Segundo Edwards e Potter (1992), a tarefa analítica da psicologia discursiva é investigar o modo como as diferentes explicações e descrições sobre o self são construídas, incluindo, para tanto, uma análise de como estas são produzidas relacionalmente. Segundo Potter e Wetterell (1996), um conceito importante para o entendimento de como o self se expressa no discurso é a noção de repertório interpretativo. Estes podem ser entendidos enquanto recursos sociais, “... sistemas de termos usados para caracterizar e avaliar ações, eventos e fenômenos (p.149). As pessoas recorrem a diferentes repertórios interpretativos para atingirem propósitos sociais, de acordo com as particularidades dos relacionamentos nos quais participam.

Para estes autores, uma análise das práticas discursivas situada nesta perspectiva guarda estreita relação com a esfera da política e da ética. Entende-se que o uso de determinados repertórios, nos quais noções específicas de self são favorecidas, implica não apenas na garantia de algumas formas de descrição e explicação das ações individuais, mas também na manutenção de relações de poder e padrões de dominação e subordinação. Ao construir o self de um determinado modo, outras construções são restringidas, de forma que a criação de um tipo de self ou subjetividade no discurso também cria um tipo particular de sujeição.

De acordo com Edwards e Potter (1992), esta perspectiva discursiva redefine o conceito de linguagem - que passa a ser necessariamente associado ao conceito de ação, bem como a noção de self - que passa a ser entendido como o discurso sobre o self, com uma ênfase particular sobre o uso que as pessoas fazem de determinados repertórios interpretativos e sobre as funções pragmáticas das descrições de si mesmo.

Para Burr (2000), a psicologia discursiva de Potter e colaboradores e a visão de self, que a atravessa, são marcadas pelo esforço de deslocar o locus de significação individual, característica das propostas mais tradicionais em psicologia, para a esfera do social. Estes autores falam de uma pessoa que se apropria de repertórios interpretativos, fazendo uso dos mesmos de acordo com as demandas e possibilidades definidas pelas ordens morais locais, com a finalidade de justificar ações, comportamentos, críticas, etc.

Em síntese, podemos destacar, como aspecto central na obra destes autores, a afirmação do caráter performático da linguagem. Isto chama nossa atenção para: as implicações de determinados discursos de self para a construção de determinados relacionamentos e realidades sociais; para as relações de "poder" entre as pessoas e a importância desta categoria na regulação dos relacionamentos em nossa sociedade; e para a comunidade linguística que disponibiliza alguns repertórios interpretativos, assim delimitando as possibilidades de significação em uma determinada cultura.

\section{A teoria do posicionamento e a construção discursiva de identidade}

Também a teoria do posicionamento pode ser destacada, no conjunto das propostas construcionistas, por suas contribuições para o entendimento da natureza do self e dos processos de construção da identidade na linguagem e nos relacionamentos. Tal como proposta por Davies e Harré (1999), esta teoria busca compreender a especificidade das conversações através da definição de três conceitos centrais: posição, força social da ação e linha de história. Entende-se por posição,

“...um grupo complexo de atributos pessoais genéricos, estruturado de vários modos, que influenciam nas possibilidades de ação pessoal, intergrupal ou mesmo intrapessoal, através de algumas designações de direitos, deveres e obrigações a um indivíduo, conforme sustentando pelo grupo"(Harré \& Van Langenhove, 1999b, p. 1)

Este conceito de posição remete aos lugares sociais assumidos e negociados pelas pessoas em suas conversações. Através dele, busca-se contemplar o dinamismo implicado nos processos de construção de identidade, entendendo que é apenas no momento presente de uma interação que as diversas posições de self adquirem sentido.

Entende-se, nesta perspectiva, que as pessoas estão sempre engajadas em atividades discursivas onde posicionam a si mesmas e aos outros, mas as formas que estes posicionamentos assumem vão diferir de acordo com as normas sociais que regulam estas interações e com as situações específicas em que eles ocorrem. Neste sentido, tanto a linha de história como a força social dos atos discursivos influenciam a dinâmica dos posicionamentos negociados entre os interlocutores.

A linha de história refere-se ao conjunto de significados associados pelos falantes à posição negociada, e que permite definir o sentido de uma posição em uma determinada interação. Ela é desenvolvida tanto a partir da história conversacional imediata, ou seja, do desenvolvimento da conversa entre os interlocutores naquele momento interativo específico; bem como da seqüência de coisas já ditas em outros relacionamentos, ou seja, das experiências anteriores de significação.

O posicionamento também está relacionado à força social implicada no ato de assumir ou atribuir ao outro determinada posição. Esta refere-se ao “... poder presente nos enunciados na construção das práticas sociais e de realidades conversacionais" (Van Langenhove \& Harré, 1999b). Este conceito sustenta-se na noção de linguagem em uso proposta por Wittgeinstein, em que a linguagem é considerada, em si mesma, uma prática social. Ao falar, as pessoas realizam ações, onde posições são negociadas de acordo com determinados propósitos sociais e levando a determinadas conseqüências para esta interação em curso (Davies \& Harré, 1999)

A especificidade do conceito de posicionamento reside, portanto, em seu caráter constitutivo: o selfé construído nas práticas discursivas, através das posições que as pessoas negociam ativamente, em seus relacionamentos. Assim, a noção de identidade como unidade é substituída pela possibilidade de múltiplas descrições de selves,

\footnotetext{
“... a questão da identidade (do quem sou eu?) é sempre uma questão aberta, cujas respostas dependem das posições assumidas por um ou por outro nestas práticas discursivas, e das
} 
histórias através das quais damos sentidos a nossas vidas e a dos outros" (Davies \& Harré, 1999, p. 35).

Esta definição rompe com qualquer noção essencialista, que pressupõe um self localizado interiormente ou que se revela parcialmente através de "verdadeiras" histórias autobiográficas. Não existe uma única biografia real, construída sobre experiências vividas, mas sim a construção sempre atual e situada de selves, variável de acordo com os relacionamentos em curso.

\section{Self narrativo e a estrutura das explicações narrativas}

Também Gergen (1994) busca refletir sobre a constituição do self no discurso, recorrendo a noção de self narrativo. Esta refere-se às narrativas e explicações que as pessoas desenvolvem sobre si mesmas, através da organização temporal de eventos pessoais, quando então estabelecem conexões entre eventos vividos, na tentativa de construção de uma história que as tornem inteligíveis a elas mesmas e aos outros.

Segundo Gergen (1994), “as narrativas são recursos conversacionais, construções abertas à contínua alteração à medida em que uma interação progride" (p.188), sendo o self produzido dentro de seqüências conversacionais de ação. Em sua concepção, o self narrativo funciona como histórias orais dentro de uma sociedade, que são usadas como recursos culturais, com diferentes propósitos sociais, como de auto-identificação, auto-justificação e solidificação social, por exemplo.

Para ele, estamos sempre sendo avaliados acerca da inteligibilidade e realidade das histórias pessoais que construímos, uma vez que existem normas que delimitam o que vem a ser considerado como uma "narrativa bem formada" em uma sociedade, e que dão às nossas descrições de self e de mundo um senso de realidade. Na cultura ocidental, algumas características são exigidas para garantir a inteligibilidade das narrativas e dar a elas o efeito retórico de veracidade e realidade valorizados na contemporaneidade, quais sejam: a) estabelecer um desfecho valorizado; b) selecionar eventos relevantes para o desfecho; c) ordenar os eventos importantes - geralmente através de uma seqüência linear, temporal; d) construir uma identidade estável ao longo do tempo; e) estabelecer ligações causais, construindo explicações para o resultado; e f) utilizar sinais de demarcação indicativos da sequiência narrativa (seu início, meio e fim).

Segundo Gergen, nossa participação em um universo cultural nos expõe a uma amplitude de formas narrativas ${ }^{3}$. Potencialmente, podemos fazer uso de todas elas, de acordo com as contingências do processo conversacional e com o modo como desejamos nos contar ao mundo e a nós mesmos. Contudo, não somos livres para construir qualquer história pessoal, pois as convenções sociais valorizam e convidam certas descrições de self, enquanto desencorajam outras. Além disso, este autor destaca que a possibilidade de uma pessoa sustentar determinadas narrativas de self depende fun-

3 Este autor sugere alguns tipos de narrativa típicos da sociedade ocidental, nos quais qualquer forma de enredo linear pode ser classificada: a narrativa estável, a narrativa progressiva e a narrativa regressiva. Estas geralmente constituem as bases para outras variações mais complexas (Gergen, 1994). damentalmente de seu relacionamento com os outros. Esta interdependência das narrativas resulta em um importante aspecto da vida social que é a formação de uma rede de identidades recíprocas. Ou seja, uma identidade pode apenas ser mantida enquanto outros desempenham papéis apoiadores na construção da mesma. A presença de um outro (presente ou imaginário) é essencial, sendo o desenvolvimento de uma narrativa de self sempre um processo de co-autoria:

\footnotetext{
"O self não é fundamentalmente uma propriedade do indivíduo, mas dos relacionamentos - produto do intercâmbio social. De fato, ser um self com um passado e um futuro potencial não é ser um agente independente, único e autônomo, mas ser imerso na interdependência" (Gergen, 1994, p. 186).
}

Ao enfatizar o caráter dinâmico e flexível do self, situando-o enquanto uma produção lingüística e relacional, Gergen questiona o caráter ontológico de uma identidade individual, unitária e contínua. Mais especificamente, ao problematizar as formas mentalistas de discurso sobre o self, típicas na sociedade ocidental, e questionar o caráter ontológico de seus predicados, este autor situa o discurso mental no universo social, ressaltando sua função performática - ou seja, enfatizando que estas formas de descrição sobre o self trazem determinadas conseqüências, possibilitando determinadas práticas sociais e restringindo outras. Nesta perspectiva, o foco recai sobre as funções sociais e políticas das formas de descrição de self que utilizamos em nossas conversações (Gergen ,1989; Kitzinger, 1989; Shotter, 2000).

Em síntese, podemos dizer que as perspectivas construcionistas apresentadas ilustram algumas tendências presentes neste campo sobre o entendimento do self e, a despeito das diferenças entre elas, alguns pontos semelhantes podem ser destacados.

Entender o self como discurso, revisando e reconhecendo os inúmeros sentidos que informam nosso entendimento sobre o que é uma pessoa constitui-se elemento comum, embora com diferentes ênfases, entre as três perspectivas apresentadas. Este tipo de entendimento sustenta um olhar sobre as formas culturalmente situadas de descrição, rompendo com as visões essencialistas sobre a natureza do mundo social e do self. Além disto, ele favorece uma análise das implicações das nossas formas de descrição para a sustentação de determinadas práticas e formas de vida, uma vez que se baseia na noção de linguagem como constitutiva (e não representativa) do self e do mundo e de seu caráter performático (linguagem como ação). Também estas perspectivas destacam a importância do relacionamento eu-outro, que passa a ser descrito como constitutivo do que vem a ser uma pessoa. Portanto, o foco de investigação sobre o self deixa de ser o indivíduo e passa a ser o relacionamento.

\section{Um diálogo entre metapsicologia e construcionismo social}

Entendemos ser consensual entre as descrições psicanalíticas aqui descritas a pressuposição de um complexo mundo interno e de um aparelho psíquico, cujo funcionamento é marcado pela dinâmica de processos mentais inconscientes - aspectos estes que agrupam estas diferentes perspectivas 
sob o domínio de uma metapsicologia. Contudo, ainda que tendo por sustentação as proposições de Freud, estas diferentes abordagens apresentam algumas diferenças importantes entre si.

A principal tensão entre a psicologia do ego e a teoria das relações objetais reside na ênfase dada à influência do ambiente externo e das relações experienciadas na infância para a constituição e desenvolvimento do mundo psíquico. Enquanto a psicologia do ego enfatiza a importância das pulsões e dos processos dinâmicos interiores na organização do psiquismo, a teoria das relações objetais, embora não negue este aspecto, focaliza a importância das relações vividas na infância. Assim, parece compreensível que a psicologia do ego se preocupe especialmente com a descrição do ego enquanto um aspecto estrutural do psiquismo humano, enquanto os teóricos das relações objetais utilizem preferencialmente o termo self, assim focalizando a noção de "pessoa em relação", considerando a pessoa uma instância física, total.

Contudo, esta diferença de foco entre os defensores de uma psicologia do ego e os teóricos das relações objetais não tem sido tão problematizada como a proposição de Kohut de uma psicologia do self. Alguns teóricos tradicionais da psicanálise entendem que a pouca ênfase dada por este autor à teoria pulsional e aos aspectos estruturais do psiquismo humano acaba por descaracterizar esta proposta enquanto uma compreensão psicanalítica, situando-a em um campo teórico-clínico mais próximo do existencialismo e de aspectos psicossociais. Embora não pretendamos entrar neste campo de tensão, pensamos que, a despeito de suas especificidades, a proposição de Kohut de uma psicologia do self mantém-se no campo das descrições psicanalíticas, uma vez que preserva as noções de inconsciente, descrevendo a importância das experiências vividas na infância em termos das representações internas produzidas nas relações interpessoais. Assim, ainda que a ênfase recaia sobre a influência do ambiente externo e das relações vivenciadas, o foco persiste sobre o indivíduo e os modos como ocorre a organização psíquica de sua experiência emocional.

Assim, refletindo sobre estas diferentes perspectivas psicanalíticas, concluímos pela existência de uma descrição essencialmente dualista acerca da constituição da subjetividade e do psiquismo humano. Em todas estas formulações, há a pressuposição de um mundo interno (pulsões, defesas, ansiedades) em oposição a um mundo externo (ambiente, relações vividas, experiências, frustrações). Mesmo quando se defende a importância dos relacionamentos vividos para a constituição do self, esta dualidade está presente - o self é descrito como estando em relação a algo externo a ele. A relação, assim, não constitui a unidade de descrição, mas um elo entre dois pólos distintos.

Portanto, ao propor um mundo psíquico, descrito de formas particulares, a psicanálise constrói um discurso ontológico acerca do humano, no qual conceitos como psiquismo, inconsciente, mundo interno, ambiente externo, figuras parentais, representações mentais, conflitos, pulsões, mecanismos defensivos, ansiedade, entre outros, têm lugar de destaque. Todas estas descrições fazem da psicanálise uma ciência particular, que oferece uma teoria sistematizada e explicativa acerca da vida mental e do funcionamento psíquico. De modo contrário, ao invés de se propor uma teoria que busca explicar a natureza do mundo e do self, o construcionismo social desponta como uma metateoria (Gergen, 1994), isto é, uma "teoria sobre a teoria", sobre o modo como construímos explicações sobre o mundo em que vivemos e de nossas relações com ele.

Tal como vemos, dois aspectos atravessam o entendimento das abordagens construcionistas sobre o self, ambos podendo ser vistos como indissociados, sendo separados aqui apenas por uma função explicativa: 1) o entendimento do self enquanto um discurso; e 2) o caráter relacional e discursivo do self ou da identidade.

Este primeiro aspecto refere-se ao fato de que o construcionismo não descreve o self enquanto uma entidade intrínseca, individual e essencial, mas sim como um discurso construído socialmente. Entender o self como discurso implica em dirigir uma atenção especial sobre os sentidos que atravessam o entendimento do que é ser uma pessoa em nossa cultura e sobre as implicações de seu uso para o modo como nos relacionamos e construímos nossas práticas sociais. Isto encoraja uma investigação sobre a multiplicidade das construções de self e sobre as funções sociais e interpessoais de determinadas formas de descrição. Além disso, a natureza culturalmente situada das conceitualizações de self é enfatizada (diferentes grupos podem fazer uso de diferentes descrições de self), sendo remetidas ao domínio da linguagem e dos relacionamentos. Em nossas interações, fazemos uso de diversas descrições pessoais, nos reconhecendo com determinadas características, jeitos de ser, traços de personalidade, etc. Estes modos de descrição são regulados pela cultura e partilhar destes sentidos é garantir formas de inteligibilidade e de participação em relacionamentos sociais onde estas descrições se fazem fundamentais. Portanto, ser uma pessoa, e ser reconhecida por outros como tal, implica em se descrever de determinadas maneiras, construindo uma história pessoal que seja coerente e inteligível dentro de uma comunidade lingüística.

O segundo aspecto refere-se às propostas de entendimento de como, então, se constrói esse self discursivo. Aqui, o foco recai sobre os relacionamentos e sobre os diferentes modos como as pessoas, em suas práticas discursivas, produzem explicações sobre si mesmas e sobre os outros. Trata-se, portanto, de uma tentativa de explicação de como se dá o processo de produção de sentidos sobre o self, através da participação das pessoas em práticas discursivas.

Contudo, este segundo aspecto traz uma tensão: ao tentar explicar como se dá os processos de significação, não estaria também o construcionismo produzindo uma descrição ontológica, onde a tese de um self discursivo e construído socialmente é afirmada? Para Gergen (1994), afirmar o caráter construído do mundo implica também em considerar a proposta construcionista como um discurso, que emerge num contexto social e histórico particular. Portanto, adotar a visão construcionista implica em manter viva a postura de crítica e reflexão, inclusive de seus próprios predicados.

Partindo destas questões, uma distinção possível entre as teorias psicanalíticas e o construcionismo social é que as primeiras fundamentam-se em uma metapsicologia, constituindo-se, assim, como teorias que buscam explicar o funcionamento humano, a partir da pressuposição de um complexo aparelho psíquico e de fenômenos inconscientes. 
Nestas abordagens, as noções de ego ou self assumem o lugar de descrições universais, sendo naturalizadas e legitimadas pela ciência psicanalítica, que, por sua vez, está pautada pela busca por descrições gerais e universais acerca do funcionamento humano. Ao contrário, o construcionismo social, que chega à psicologia inicialmente por meio da psicologia social, enfatiza a importância dos relacionamentos e da linguagem na formação do self. Deste modo, este não se coloca como uma teoria, como uma explicação ontológica sobre a natureza do self e do funcionamento humano, mas sim como uma ferramenta crítica, que aponta para o modo como, socialmente, construímos sentidos sobre o mundo e sobre nós mesmos, e para o modo como estes organizam nossas vidas e práticas sociais.

No construcionismo, o próprio fenômeno psicológico (bem como o self) é problematizado enquanto um existente em si mesmo ou uma conceituação a priori. A partir disso, a psicanálise e outras descrições psicológicas ou sociais (incluindo a própria descrição construcionista) passam a ser consideradas como discursos construídos socialmente, a partir dos quais se propõe um determinado conhecimento sobre o mundo e sobre o ser - conhecimento este legitimado pela ciência, enquanto prática social situada, e válido para determinados fins e contextos.

Assim, as diferenças existentes entre as propostas psicanalíticas e construcionistas sociais, dificilmente podem ser consideradas através de uma comparação linear entre as mesmas, buscando equivalentes entre suas descrições. Estas diferenças derivam de fundamentos epistemológicos distintos, isto é, de diferentes modos de se entender e compreender o conhecimento científico. Enquanto as teorias psicanalíticas propõem uma explicação universal sobre o funcionamento psíquico e sobre o self, o construcionismo social questiona a possibilidade de uma explicação universal e a priori (fora da linguagem), e busca, ao contrário, descrever o modo como construímos, em contextos sempre particulares e situados, sentidos sobre o mundo e sobre o self. Assim, o construcionismo, enquanto uma perspectiva crítica, acaba por refletir sobre o processo social de produção de sentidos e sobre a função dos mesmos na construção de práticas sociais.

Estas diferenças epistemológicas no modo como as teorias psicanalíticas e as abordagens construcionistas sociais compreendem o self derivam, conseqüentemente, em diferentes propostas de intervenção para o contexto clínico. Enquanto as teorias psicanalíticas fazem uso da técnica psicanalítica enquanto método de tratamento, explorando a dinâmica dos processos mentais inconscientes e suas implicações para a organização da experiência individual, o construcionismo busca novas concepções sobre a prática clínica, entendendo a terapia enquanto espaço dialógico, um contexto de conversação, de organização e re-descrição de sentidos.

Diversos autores têm se apropriado do discurso construcionista social, promovendo algumas alterações em suas práticas clínicas e sugerindo algumas propostas práticas de intervenção - tais como White e Epston (1990); Anderson (1997) e Andersen (1999). No entanto, o construcionismo não deriva necessariamente numa proposta de técnica ou modelo de intervenção clínica. Mas, seu convite à reflexão sobre o caráter construído de nossos discursos de self, de mundo e, em última instância de nossas próprias teorias, pode sim favore- cer uma nova postura terapêutica - como por exemplo, a partir da reconsideração da relação terapeuta cliente, da atenção ao papel do terapeuta na construção de determinadas realidades de mundo e de self e das implicações éticas subjacentes ao uso de alguns discursos psicológicos.

Em síntese, entre algumas diferenças entre as propostas construcionistas e as psicanalíticas, destacamos que:

a) enquanto as teorias psicanalíticas se sustentam na proposição de uma metapsicologia, assim descrevendo ego ou self em relação a um aparelho psíquico interno e à existência de fenômenos mentais inconscientes, o construcionismo social entende o self como discurso, dando à linguagem e ao relacionamento um lugar de destaque;

b) enquanto as teorias psicanalíticas situam o ego ou self enquanto uma unidade interior essencial, o construcionismo atenta para o caráter construído e, portanto, não universal / essencial dos fenômenos psicológicos, compreendendo-os como sendo construídos pelas pessoas em seus relacionamentos. O self, assim, é entendido como um produto das práticas discursivas e o foco de investigação recai sobre as implicações sociais de determinadas formas de descrição;

c) por fim, ainda que teorias psicanalíticas afirmem a importância do relacionamento na constituição do self, este é visto normalmente como uma entidade em relação. Para o construcionismo, ao contrário, a relação é a unidade de descrição - é na relação que as pessoas se constituem, ou seja, o self é visto como uma "realização retórica", um produto da "ação-conjunta" (Shotter, 2000) entre as pessoas.

Esperamos que este artigo, ao favorecer uma breve aproximação entre o construcionismo social e outras perspectivas teóricas em psicologia, amplie as possibilidades de diálogo entre estudiosos e profissionais da área clínica.

\section{Referências}

Aurélio, B.H.F (1977). Minidicionário da língua portuguesa. Rio de Janeiro: Editora Nova Fronteira S.A. (6 ${ }^{\mathrm{a}}$ edição)

Anderson, H. (1997). Conversation, language and possibilities - a post-modern approach to therapy. New York: Basic Books.

Andersen, T. (1999). Processos reflexivos. (Rosa Maria Bergallo, Trad.). Rio de Janeiro, Instituto Noos / ITF (Originalmente publicado em 1991).

Burr, V. (2000). An introduction to social constructionism. London: Routledge. (Originalmente publicado em 1995).

Blum, H.P. (1982). Theories of the self and psychoanalytic concepts: discussion. Journal of the American Psychoanalytic Association, 30(4), pp. 959-978.

Brenner, C. (1987). Noções básicas de psicanálise: introdução à psicologia psicanalítica. (Ana Mazur Spira, Trad.). $5^{\mathrm{a}} \mathrm{ed}$, Rio de Janeiro: Imago.

Daniel, P. (1994). Análise de crianças e o conceito de fantasia inconsciente. In: R. Anderson (Org). Conferências clínicas sobre Klein e Bion. (pp. 27-36). (Belinda Mandelbaum: Trad.). Rio de Janeiro: Imago.(Originalmente publicado em 1992).

Davies, B. \& Harré, R. (1999). Positioning and personhood. In: R. Harré \& L. Van Langenhove (Orgs.) (1999). Positioning the- 
ory: moral contexts of intentional actions (pp. 32-52). Oxford: Blackwell Publishers.

Edwards, D. \& Potter, J. (1992). Discursive psychology. London: Sage Publications.

Freud, S. (1969). A psicologia dos processos oníricos. In: J. Salomão (Org). Edição standard brasileira das obras completas de Sigmund Freud (vol. V, parte II, pp. 541-652). Rio de Janeiro: Imago Editora. (originalmente publicado em 1900).

Freud, S. (1969). Três Ensaios sobre a Teoria da Sexualidade. In: J. Salomão (Org). Edição standard brasileira das obras completas de Sigmund Freud (vol. VII, pp. 117-229). Rio de Janeiro: Imago Editora. (Originalmente publicado em 1905).

Garcia-Rosa, L.A. (1995). Artigos de metapsicologia: narcisismo, pulsão, recalque, inconsciente (1914-1917). (Introdução à metapsicologia freudiana). Rio de Janeiro: Jorge Zahar Editora

Gabbard, G.O. (1998). Psiquiatria psicodinâmica - baseado no DSM-IV. (Luciana N. de A. Jorge e Maria Rita Secco Hofmeinter, Trad.). Porto Alegre: Artes Médicas, $2^{\mathrm{a}}$ edição (Originalmente publicado em 1994).

Gergen, K.J. (1989). Warranting voice and the elaboration of the self. In: J. Shotter \& K.J. Gergen (Ed) (1989). Texts of identity. (pp.70-81). London: Sage Publications.

Gergen, K.J. (1994). Realities and relationships - soundings in social construction. Harvard University Press.

Harré, R (1998). The singular self-an introduction to the

psychology of personhood. London: Sage Publications Inc.

Harré, R. \& Van Langenhove, L. (Orgs.) (1999a). Positioning theory: moral contexts of intentional action. Oxford: Blackwell Publishers.

Harré, R. \& Van Langenhove, L. (1999b). The dynamic of social episodes. In: R. Harré \& L. Van Langenhove (Orgs.) (1999). Positioning theory: moral contexts of intentional actions (pp. 01-13). Oxford: Blackwell Publishers.

Havens, L. (1986). A theoretical basis for the concepts of self and authentic self. Journal of the American Psychoanalytic Association, 34(2), pp. 363-378.

Hinshelwood, R.D. (1992). Dicionário do pensamento kleiniano. (Elisa Dias Velloso, Trad.). Porto Alegre: Artes Médicas.

Kaplan, H.T; Sadock, B.J. \& Grebb, J.A. (1997). Compêndio de psiquiatria - ciências do comportamento e psiquiatria clínica. Porto Alegre: Artes Médicas (Originalmente publicado em 1994)

Kernberg, O.F. (1982). Self, ego, affects and drives. Journal of the American Psychoanalytic Association, 30(4), pp.893-917.

Khan, M.M.R. (1993). Prefácio 1. In: Textos selecionados: da pediatria à psicanálise (Jane Russo: Trad.). Rio de Janeiro: Francisco Alves, $4^{\mathrm{a}}$ ed. (Originalmente publicado em 1958).

Kitzinger, C. (1989). Liberal humanism as an ideology of social control: the regulation of lesbian identities. In: J. Shotter \& K.J.Gergen (Ed) (1989). Texts of identity. (pp. 82-98). London: Sage Publications Inc .

Klein, M. (1970). O início do desenvolvimento da consciência na criança. In: M. Klein; M. Kris; S. Lorand; E. Glover; C.P. Obendorf; T.A. Ames \& I.T. Broadwin. A psicanálise hoje: aproximação moderna aos problemas humanos. (pp. 01-15). (Elisa Dias Velloso, Trad.). Rio de Janeiro: Imago. (Originalmente publicado em 1944).

Kohut, H. (1988). Psicologia do self e a cultura humana - reflexões sobre uma abordagem psicanalítica. (José Octávio de Aguiar Abreu, Trad.). Porto Alegre: Artes Médicas.
Mello Filho, J. de (1995). O ser e o viver: uma visão da obra de Winnicott. Porto Alegre: Artes Médicas, $1^{a}$ edição revisada. (Originalmente publicado em 1989).

Meissner, W.W. (1986). Can psychoanalysis find its self?. Journal of the American Psychoanalytic Association, 34(2), pp. 379400.

Potter, J. \& Wetherell, M. (1996). Discourse and social psychology: beyond atitudes and behavior. London: Sage Publications Inc (Originalmente publicado em 1987).

Sampson, E.E. (1989). The deconstruction of the self. In: J. Shotter \& K.J. Gergen (Orgs.) (1989) Texts of identity. (pp. 01-19). London: Sage Publications Inc .

Santos, M.A. (1999). A constituição do mundo psíquico na concepção winnicottiana: uma contribuição à clínica das psicoses Psicologia: Reflexão e Crítica, 12(3), 603-625.

Segal, H. (1975). Introdução à obra de Melanie Klein. (Júlio Castanõn Guimarães, Trad.). Rio de Janeiro: Imago Editora. (Originalmente publicado em 1964).

Shotter, J. (1989). Social accountability and the social construction of 'you'. In: J. Shotter \& K.J. Gergen (Orgs.) (1989). Texts of identity. (pp. 133-151). London: Sage Publications Inc.

Shotter, J. (1993). Becoming someone: identity and belonging. In: N. Coupland \& J.F. Nussbaun (Orgs.) (1993). Discourse and lifespan identity. Language and language behaviour, v.4. (pp. 05-27) California: Sage Publication Inc.

Shotter, J. (1998). Life inside the dialogically structured mind: Bakhtin's and Volosinov's account of mind as out in the world between us. [online] (retirado em 10/11/1998). Disponível em http://massey.ac.nz/ Alock/virtual/inner.htm.

Shotter, J. (2000). Conversational realities: constructing life through language. Inquires in social construction.. London: Sage (Originalmente publicado em 1993).

Steiner, J. (1994). O equilíbrio entre as posições esquizoparanóide e depressiva. In: R. Anderson (Org). Conferências clínicas sobre Klein e Bion. (pp.60-72). (Belinda Mandelbaum, Trad.). Rio de Janeiro: Imago (Originalmente publicado em 1992).

Ticho, E.A. (1982). The alternate schools and the self. Journal of the American Psychoanalytic Association, 30(4), pp. 849-862.

Van Langenhove, L. \& Harré, R. (1999). Introducing positioning theory: the dinamic of social episodes. In: R. Harré \& L. Van Langenhove (Orgs.) (1999). Positioning theory: moral contexts of intentional actions (pp. 14-31). Oxford: Blackwell Publishers.

Winnicott, D.W. (1993a). Desenvolvimento emocional primitive (Originalmente publicado em 1945) (pp. 269-286). In: Textos Selecionados: da pediatria à psicanálise (Jane Russo, Trad.). Rio de Janeiro: Francisco Alves, $4^{\mathrm{a}}$ ed.

Winnicott, D.W. (1993b). Psicose e cuidados maternos (Originalmente publicado em 1952) (pp. 375-387). In: Textos selecionados: da pediatria à psicanálise. (Jane Russo, Trad.). Rio de Janeiro: Francisco Alves, $4^{\mathrm{a}}$ ed.

Recebido em 24.07.2002

Primeira decisão editorial em 27.06.2003

Versão final em 06.08.2003

Aceito em 29.08.2003 